\title{
ANÁLISES NO ISOLAMENTO ACÚSTICO EM SALAS DE MÚSICA DA UNIVERSIDADE DO SAGRADO CORAÇÃO - USC
}

\section{ANALYSIS ON ACOUSTIC INSULATION IN MUSIC ROOMS OF THE UNIVERSITY OF THE SACRED HEART - USC}

\author{
Kátia Regina Saggin ${ }^{1}$, Patrícia Adriana Marques de Andrade ${ }^{2}$, Camila Mayumi Nakata ${ }^{3}$
}

Recebido em 30 de dezembro de 2012; recebido para revisão em 10 de janeiro de 2012; aceito em 17 de janeiro de 2013; disponível on-line em 19 de fevereiro de 2013.

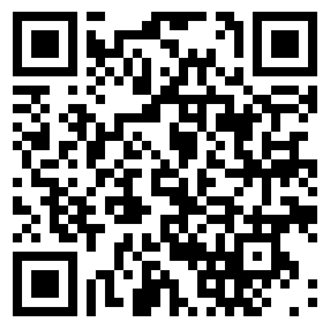

PALAVRAS CHAVES:

Acústica;

Conforto acústico;

Desempenho acústico;

Isolamento acústico.

\section{KEYWORDS:}

Acoustic;

Acoustic insulation:

Acoustic comfort;

Acoustic performance.

\footnotetext{
* Contato com os autores:

${ }^{1}$ e-mail : katia_saggin@hotmail.com (K. R. Saggin)

Graduanda do Curso de Arquiteta e Urbanista da Universidade Sagrado Coração (USC)

22e-mail : patrícia_pama@hotmail.com (P. A. M. de Andrade)

Graduanda do Curso de Arquiteta e Urbanista da Universidade Sagrado Coração (USC)

${ }^{3}$ e-mail : camilanakata@yahoo.com.br (C. M. Nakata)

Doutoranda da Universidade Federal de São Carlos (UFSCar)
}

ISSN: 2179-0612

C) 2013 REEC - Todos os direitos reservados.
ABSTRACT: It is considered that the study of the propagation of noise and forms of reatment for sound insulation are very important to performance improvements of vironments for teaching. When it comes to music teaching environments, these should for boundproofing and for sound absorption, important for comfort and care must be taken both in the environments as in post-occupation. This study aims to analyze the 列 Thus it is considered relevant to $p$ improvement in acoustic performance of these rooms, avoiding extraneous noises that interfere with the learning of students who use these. 


\section{INTRODUÇÃO}

Um ambiente fechado é entendido como um ambiente em que temos o controle de suas condições físicas como temperatura, umidade, ventilação, tempo de reverberação entre outros. Todos os estudos que já foram realizados para que se possa entender como funcionam algumas propriedades acústicas de ambientes fechados se deram de forma empírica. Busca-se um parâmetro de referência para estabelecer relações físicas, materiais e geométricas com todas as particularidades de cada item que compõem o espaço arquitetônico (GOUVÊA, 2010).

Recomenda-se que cada ambiente atenda o conforto acústico de acordo com a NBR 10152 (Nível de ruído para conforto acústico). O nível de ruído para o conforto acústico estabelecido pela norma depende da atividade realizada no ambiente.

Rocha (2010) afirma que os critérios acústicos adotados em sala de prática (ensino) e ensaio de instrumento e canto devem privilegiar características que propiciem o ensino e a aprendizagem, ou seja, que permitam ao aluno aprender e praticar para ter o máximo desenvolvimento como intérprete.

Segundo Rocha (2010) as salas para ensino de música devem propiciar ao estudante de música o máximo aproveitamento em relação a aspectos muito específicos do universo musical, como o senso rítmico, a articulação e a dinâmica. Logo, estudar e ensaiar em ambientes tão diferenciados e com tantas interferências de diversos tipos de ruído não propiciam as condições exigidas a estudantes e professores, que possam promover alguma qualidade ao ensino.

O ambiente tem grande importância na forma como o som se propaga. Assim, o tratamento de uma sala destinada à música deve ser adequado para não afetar a forma como os músicos percebem o som ou tocam suas músicas. As características acústicas de uma sala de concerto devem preservar as qualidades musicais de intimismo, definição, timbre, balanço e o alcance dinâmico. Devem contribuir com a plenitude do tom, altura e uma ampla gama do aumento e da diminuição da sonoridade. Além disso, deve-se tomar cuidado no tratamento para que o tempo de reverberação seja ideal ao uso.

O tempo de reverberação é o tempo decorrido do início do som na fonte até a queda do mesmo em 60 dB. Segundo Fernandes (2006), quando um som se propaga dentro de um ambiente, ao encontrar um obstáculo (como uma parede) ele se reflete voltando para o mesmo ambiente. As múltiplas reflexões do som num ambiente causa a reverberação, que é um tipo de prolongamento dos sons, muito comum em igrejas e grandes ambientes. Quando um som é emitido num ambiente reverberante, esse é escutado de forma prolongada, não devendo ser confundido com o 'eco'. Por isso, o tempo de reverberação pode ser interessante para ambientes com uso de música, mas pode também atrapalhar a audibilidade em ambientes destinados ao uso da fala.

As necessidades de educação musical quanto à frequência e à variedade dinâmica do som são muito mais amplas quando comparadas com salas de aula convencionais. Certas características acústicas são essenciais em uma sala de ensaio, inclusive volume adequado e isolamento acústico (FREIHEIT, 2002 apud ROCHA, 2010).

A realização de salas de ensino de música exige um tratamento acústico, tanto de isolamento quanto de absorção sonora, que deve considerar as necessidades específicas para cada ambiente. Não devendo, assim, serem encaradas como salas de aula comuns. A questão orçamentária pode também muitas vezes influenciar na qualidade desses ambientes.

O ruído pode ser transmitido através de elementos como piso, teto, estrutura da edificação, janelas, portas e pelos sistemas mecânicos, tais como de aquecimento, ventilação e condicionamento de ar, perturbando a atividade nas salas. Dessa forma, quando um ambiente já foi construído para exercer uma função, principalmente ao ensino de música que aqui está sendo abordado, torna-se interessante a avaliação pósocupacional para a verificação do desempenho acústico da mesma e de possíveis melhorias que possam ser feitas nos elementos construtivos, caso seja necessário.

Para a escolha do elemento de vedação mais adequado, no que diz respeito à acústica, além de conhecer as propriedades isoladas do material, é necessário se levar em conta os detalhes de execução e montagem de cada sistema e suas interferências e interligações com o meio circundante (SALES et. al., 2001).

\section{OBJETIVOS}

O objetivo deste estudo é analisar os valores de níveis de ruído de algumas salas do laboratório de música da Universidade do Sagrado Coração (USC, Bauru/SP) para realizar uma avaliação pós-ocupacional (APO) e observar quais tratamentos acústicos já existem e quais devem ser adotados nesses ambientes para que os mesmos possam ter seu desempenho acústico melhorado. 


\section{METODOLOGIA}

Para a medição do nível de ruído das salas de aula de música foi utilizado o aparelho decibelímetro (sonômetro) ITDEC 400 da marca Instrutemp. Esperou-se o tempo necessário (1 minuto) para sua estabilização e leitura de dados. Os procedimentos foram embasados nas condições gerais descritas para medição de ruído da NBR 10151 (2003) - Avaliação do ruído em áreas habitadas visando o conforto da comunidade.

As medições foram realizadas no período noturno, pois a maioria dos cursos é ministrada nesse período, e durante dois horários diferentes: às 20h30min e às $21 \mathrm{~h}$. Três diferentes salas de aula de música foram avaliadas. O primeiro horário analisado caracteriza o horário de maior nível de ruído externo, pois se trata do horário de intervalo. Já o segundo horário caracteriza o horário de aula, em que os alunos permanecem em suas salas de aula. As salas de aula de música avaliadas foram medidas em horário em que não havia alunos utilizandoas e os corredores encontravam-se vazios. Como as três salas encontram-se muito próximas entre si, foram feitas medições em pontos internos em cada sala e apenas uma medição externa em cada horário para comparação.

Em ambos os horários, foram medidas as seguintes salas: sala 7 (Figuras 1 e 2), sala 13 (Figuras 3 e 4) e sala 18 (Figuras 5 e 6). As Figuras 2, 4 e 6 indicam a localização dos pontos de medição nas plantas das salas. As salas são de paredes de alvenaria com divisórias de madeira compensada.

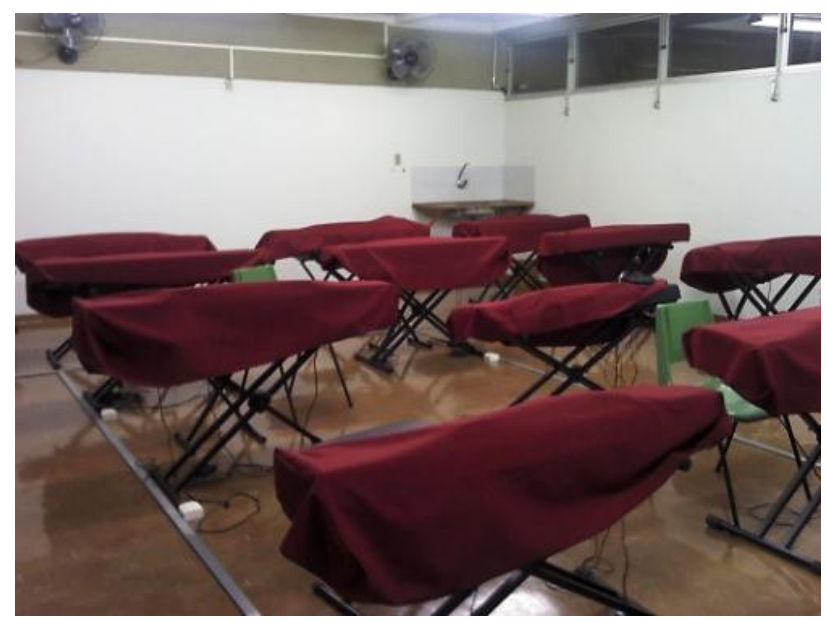

Figura 1: Sala de Música 7. Fonte: SAGGIN, ANDRADE e NAKATA (2012).

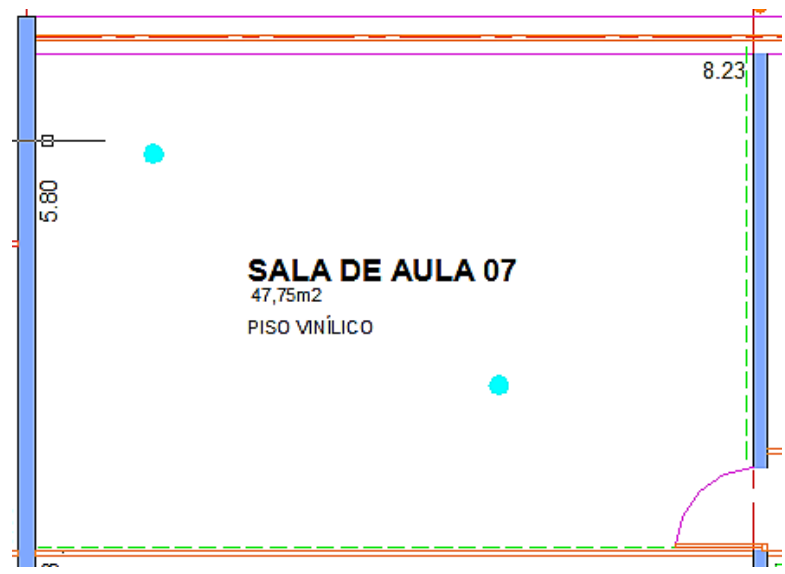

Figura 2: Sala de Música 7 com pontos de medição. Fonte: SAGGIN, ANDRADE e NAKATA (2012).

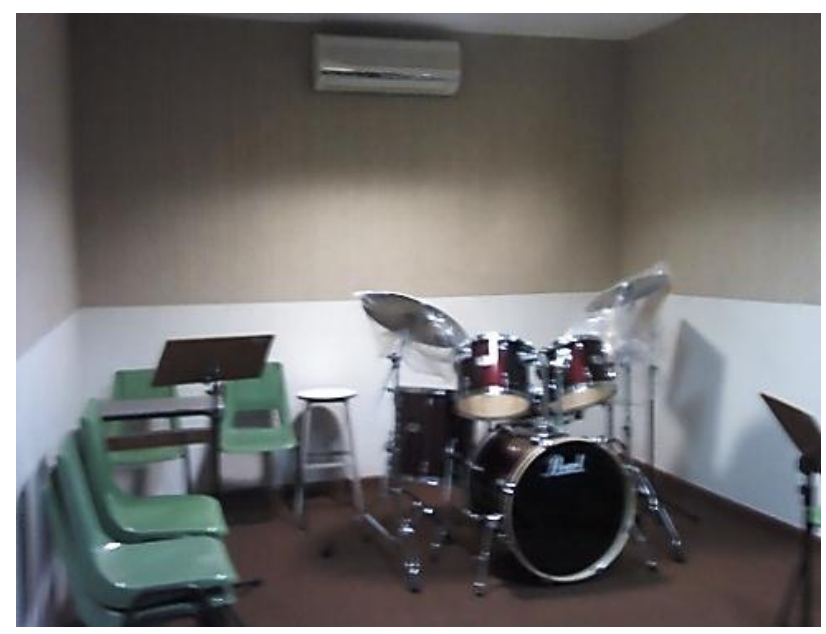

Figura 3: Sala de Música 13. Fonte: SAGGIN, ANDRADE e NAKATA (2012).

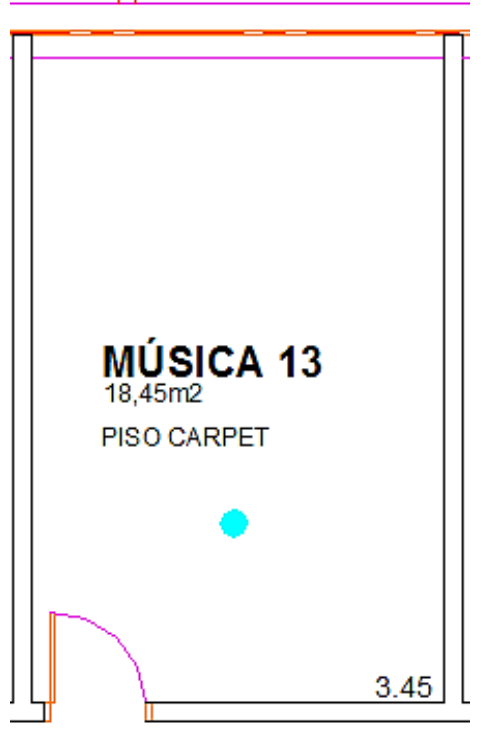

Figura 4: Sala de Música 13 com ponto de medição. Fonte: SAGGIN, ANDRADE e NAKATA (2012). 


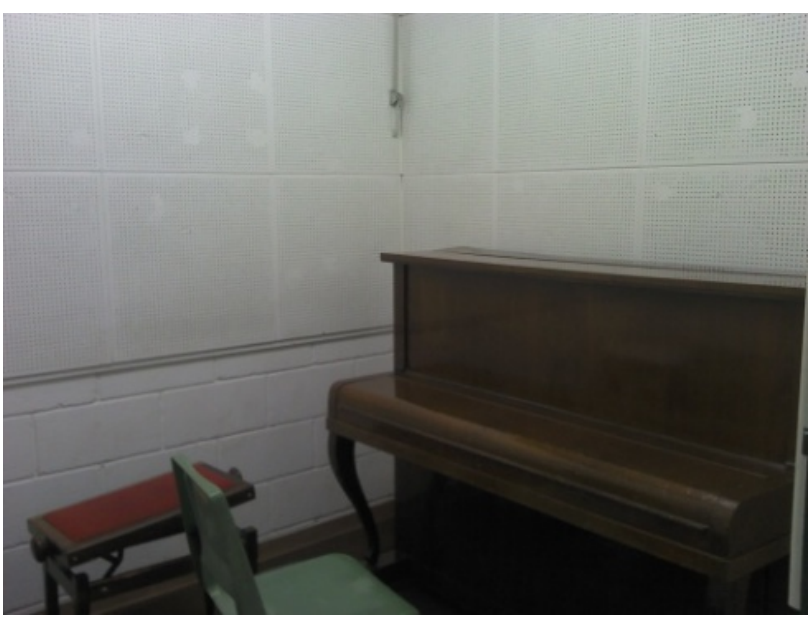

Figura 5: Sala de Música 18.

Fonte: SAGGIN, ANDRADE e NAKATA (2012).

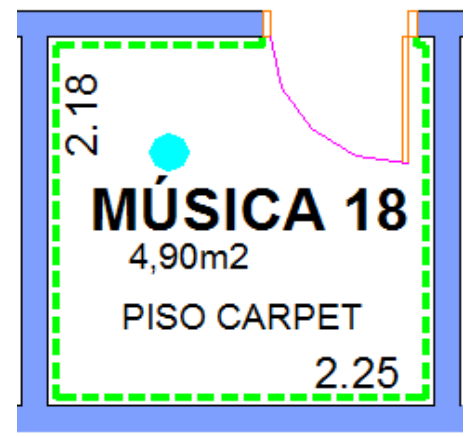

Figura 6: Sala de Música 18 com ponto de medição. Fonte: SAGGIN, ANDRADE e NAKATA (2012).

\section{RESULTADOS E DISCUSSÕES}

Os valores coletados de nível de ruído (em decibéis, dB) nas salas e horários descritos, encontramse na Tabela 1.

Das três salas que foram verificadas, a que apresentou menor valor de nível de pressão sonoro foi a sala 13 (entre 30,5 a 32,2 dB). Verifica-se na Tabela 1, que foi a sala que apresentou melhor desempenho acústico (considerando-se a diferença entre os valores medidos interna e externamente à sala). Presume-se assim que seja a sala dentre as analisadas de melhor desempenho acústico, pois possui um isolamento diferente das demais salas analisadas.

A sala que apresentou maiores valores medidos internamente foi a sala 7 (entre 47,8 a 50,3 dB). Mesmo assim, avaliando-se as condições externas, notase que o isolamento acústico foi de, aproximadamente, 13 a $15 \mathrm{~dB}$.

De acordo com a NBR 10152 (1992), que fixa o valor de 35 - 45 dB como níveis de ruído compatíveis com o conforto acústico em salas de música, a única sala que está adequada quanto ao conforto acústico seria a sala 13. As demais salas (7 e 18) apresentaram valores que excedem o mínimo ideal para o conforto acústico.

Tabela 1: Níveis de pressão sonora medidos nas salas de aula de música (em dB).

\begin{tabular}{ccccc} 
Horário & Sala & $\begin{array}{c}\text { Medição interna } \\
\text { (dB) }\end{array}$ & $\begin{array}{c}\text { Medição externa } \\
\text { (dB) }\end{array}$ & $\begin{array}{c}\text { Desempenho acústico } \\
\text { (valor ext. - int.) }\end{array}$ \\
\hline \multirow{2}{*}{ 20h30min } & 7 & 50,3 & & 12,7 \\
& 13 & 30,5 & 63 & 32,5 \\
\hline \multirow{2}{*}{ 21h } & 18 & 42,6 & & 20,4 \\
& 7 & 47,8 & 63 & 15,2 \\
& 13 & 32,2 & & 30,8 \\
\hline
\end{tabular}

\section{PROPOSTAS PROJETUAIS}

De acordo com os resultados obtidos nos ambientes analisados, pode-se concluir que duas das três salas precisam ter seu isolamento acústico melhorado.

Uma proposta de estratégias para a melhoria do isolamento acústico das salas seria o uso de painéis de concreto com alma em poliestireno, em troca do material em que atualmente compõe as divisórias. Atualmente as divisórias das salas de música são compostas de painéis industrializados (wall flex).
Os painéis industrializados analisados apresentaram valores de perda de transmissão mais baixos que a alvenaria convencional e os painéis analisados como duplos, quando comparados aos valores de isolamento sonora da alvenaria, apresentaram resultados superiores a esta.

O desempenho acústico da alvenaria convencional apresenta-se, ainda, superior à maioria dos sistemas de vedação industrializados, entretanto há alguns sistemas que oferecem resultados bem próximos da alvenaria, como os painéis de concreto maciço e os painéis de concreto com alma em poliestireno. Portanto, 
para melhorar a acústica das salas de música analisadas neste estudo seria interessante a substituição do painel existente por algum dos exemplos citados acima.

\section{CONSDIRAÇÕES FINAIS}

A partir desse experimento foi possível observar que algumas salas necessitam de uma boa melhoria quanto ao seu tratamento acústico, onde possivelmente os materiais e elementos construtivos não estão sendo adequados e acabam deixando o som ser transmitido de uma sala para outra.

A partir da analise realizada sobre os resultados obtidos, sugere-se que algumas melhorias sejam feitas nas salas para que a qualidade acústica seja melhorada, evitando que ruídos externos interfiram na sala, atrapalhando o estudo dos alunos que delas utilizam.

\section{REFERÊNCIAS BIBLIOGRÁFICAS}

Associação Brasileira de Normas Técnicas. NBR 10.151 Acústica - Avaliação do ruído em áreas habitadas, visando o conforto da comunidade - Procedimento. Procedimentos. Rio de Janeiro. 4p. 2003 (versão corrigida).

Associação Brasileira de Normas Técnicas. NBR 10.152 - Níveis de ruído para conforto acústico. Procedimento Rio de Janeiro. 4p. 1992 (versão corrigida).

FERNANDES, João Candido. Padronização das condições acústicas para salas de aula. Bauru, 2006. Disponível em: http://www.simpep.feb.unesp.br/anais/anais_13/artigos/823.p df. Acessado em: 15 de abril de 2012.

GOUVÊA, Irajá. Acústica Arquitetônica. Marília, 2010 Disponível em: < http://www.arquitetando.xpg.com.br/

acustica\%20arquitetonica.htm>. Acessado em: 23 de novembro de 2011.

PORTELA, Marcelo. Acústica de Salas - Conceitos para acústica arquitetônica. LVA/UFSC. Disponível em: http://www.labcon.ufsc.br/anexosg/391.pdf. Acessado em: 11 de novembro de 2011.

ROCHA, Letícia de Sá. Acústica e educação em música: Estudo qualitativo para sala de ensaio e prática de instrumento e canto. Curitiba, 2010. Disponível em: http://www.ppgcc.ufpr.br/dissertacoes/d0140.pdf. Acessado em: 11 de novembro de 2011

SAGGIN, Kátia Regina, ANDRADE, Patrícia Adriana Marques de, NAKATA, Camila Mayumi. Análises no Isolamento Acústico em Salas de Música da Universidade do Sagrado Coração - USC. Encontro Nacional de Tecnologia do Ambiente Construído, Juiz de Fora - MG, 2012.
SALES, U. C., NEVES, F. A., SOUZA, H. A. Avaliação comparativa do desempenho acústico de painéis de vedação pré-fabricados. In: ENCONTRO NACIONAL SOBRE CONFORTO NO AMBIENTE CONSTRUÍDO - ENCAC, 4, ENCONTRO LATINOAMERICANO SOBRE CONFORTO NO AMBIENTE CONSTRUÍDO, 3. Anais eletrônicos... São Pedro, SP, 2001, v.1, p. 1-7, 2001. 